\title{
Bonding and high-temperature reliability of NiFeMo alloy/n-type PbTe joints for thermoelectric module applications
}

\author{
Haiyang Xia · Fivos Drymiotis • Cheng-Lung Chen • \\ Aiping Wu • Yang-Yuan Chen • G. Jeffrey Snyder
}

Received: 21 August 2014 / Accepted: 3 January 2015/Published online: 24 January 2015

(C) Springer Science+Business Media New York 2015

\begin{abstract}
PbTe}$ is an extremely important thermoelectric (TE) material, due to its high TE conversion efficiency. Consequently, our effort focuses on developing PbTebased TE modules, which requires developing novel approaches for bonding metallic contacts to PbTe. In this study, $\mathrm{Fe}, \mathrm{Mo}$, and NiFeMo alloy foils were directly bonded to $n$-type $\mathrm{PbTe}$ using a rapid hot press at 600,700 , or $800{ }^{\circ} \mathrm{C}$ under a pressure of $40 \mathrm{MPa}$ and for various holding times. We find that in the case of $\mathrm{Fe}$ and $\mathrm{Mo}$, it is difficult to form a metallurgically bonded high strength joint with $\mathrm{PbTe}$. However, we find that NiFeMo alloy does effectively bond to $\mathrm{PbTe}$ at $700{ }^{\circ} \mathrm{C}$, but not at $600{ }^{\circ} \mathrm{C}$. Significant liquid $\mathrm{Pb}$, which might be due to the reaction of $\mathrm{PbTe}$ with $\mathrm{Ni}$, is found that penetrates along the $\mathrm{NiFeMo}$ grain boundaries near $\mathrm{NiFeMo} / \mathrm{PbTe}$ joints during bonding at $700{ }^{\circ} \mathrm{C}$ where the extent of liquid $\mathrm{Pb}$ penetration can be controlled with the time of bonding. Furthermore, the Seebeck coefficient of bulk PbTe with NiFeMo contacts is similar to that without NiFeMo contacts. Finally, the accelerated thermal aging of $\mathrm{NiFeMo} / \mathrm{PbTe}$ elements at
\end{abstract}

\footnotetext{
H. Xia $(\bowtie) \cdot$ F. Drymiotis · C.-L. Chen · G. Jeffrey Snyder Department of Materials Science, California Institute of Technology, 1200 E. California Blvd.,

Mail Code: 309-81, Pasadena, CA 91125, USA

e-mail: xhytsinghua@gmail.com; hyxia@caltech.edu

H. Xia · A. Wu

Department of Mechanical Engineering, Tsinghua University, Beijing 100084, China

H. Xia $\cdot$ A. Wu

Key Laboratory for Advanced Materials Processing Technology, Ministry of Education, Beijing, China

C.-L. Chen · Y.-Y. Chen

Institute of Physics, Academia Sinica, Taipei 11529, Taiwan
}

$600{ }^{\circ} \mathrm{C}$ for $240 \mathrm{~h}$ shows that the failure mechanism of $\mathrm{NiFeMo} / \mathrm{PbTe}$ joints under operating conditions is the continued formation and penetration of eutectic liquid $\mathrm{NiFeMo-PbTe}$ and liquid $\mathrm{Pb}$ along the NiFeMo grain boundaries.

\section{Introduction}

PbTe-based thermoelectric (TE) materials are used to convert heat into electrical energy; mostly for space applications. The U.S. first used PbTe $2 n / 2 p$-based SNAP$3 \mathrm{~B}$ radioisotope thermoelectric generators (RTGs) for Transit 4A and 4B in 1961. Then SNAP-9B RTGs based on $\mathrm{PbTe} 2 n / 2 p$ were developed for Transit $5 \mathrm{BN}-1$ and $5 \mathrm{BN}-2$. From 1969 to 1972, NASA used SNAP-27 RTGs based on PbTe in Apollo 12 and 14-17 missions. Then improved SNAP-19 RTGs based on PbTe 2n/TAGS-85 were developed for Pioneer 10, 11, and Viking 1, 2. In 2011, NASA launched Mars Curiosity Rover which powered by MMRTG based on PbTe 2n/TAGS-85 [1, 2]. Although NASA has employed PbTe-based RTGs for several decades, there is not much detailed information about the electrical contacts to PbTe-based elements. According to some technical reports, NASA used Ni-plated Fe caps on the cold side and Fe cups on the hot side as the contacts to PbTe for SNAP-19 RTG and MMRTG. The direct mechanical connection method, spring and piston, was employed to connect the $\mathrm{PbTe}$ elements and the contacts $[3,4]$. However, this method is complicated and leads to low efficiency of the TE device. Furthermore, PbTe-based TE devices can be employed for terrestrial applications, such as automotive and industry waste heat recovery. The direct mechanical connection method has no advantage for mass production. Some researchers from Japan bonded 
PbTe to Ni contacts by plasma activated sintering, but there was no detailed analysis of the interfacial microstructure of the PbTe contacts [5].

For a good PbTe-based TE contacts, several requirements must be met, which have been discussed in our previous paper [6]. Our previous research on $\mathrm{Ni} / \mathrm{PbTe}$ joints showed that $\mathrm{Ni}$ bonds well to $\mathrm{PbTe}$ but reacts quickly with $\mathrm{PbTe}$ [6] and therefore we are exploring alternative materials. We decided to investigate the bonding properties of $\mathrm{Fe} / \mathrm{PbTe}$ and $\mathrm{Mo} / \mathrm{PbTe}$ and subsequently those of a NiFeMo alloy. The NiFeMo alloy may work as a good interlayer since contains the reactive $\mathrm{Ni}$ but also the nonreactive (according to the literature [7]) $\mathrm{Fe}$ and Mo. The Fe and $\mathrm{Mo}$ in NiFeMo alloy might inhibit the reaction of $\mathrm{Ni}$ with $\mathrm{PbTe}$, which might increase the operating temperature and prolong the lifetime of the joints.

In this study, NiFeMo alloy foil was directly bonded to $n$-type PbTe by one-step hot-press sintering. The resulting interfacial microstructures of the $\mathrm{NiFeMo} / \mathrm{PbTe}$ joints are investigated and the phases and the distribution of elements at the $\mathrm{NiFeMo/PbTe}$ interface are analyzed. The obtained data are used to get the optimal bonding parameters and estimate the quality of the $\mathrm{NiFeMo/PbTe}$ joints. The Seebeck coefficients of bulk PbTe with and without NiFeMo contacts are measured to study the effect of the bonding process on the TE properties of PbTe. Additionally, an accelerated thermal aging experiment of $\mathrm{NiFeMo/PbTe} \mathrm{TE}$ elements is conducted in order to determine the failure mechanism and estimate the lifetime of the NiFeMo/PbTe joints.

\section{Experimental procedure}

Polycrystalline $\mathrm{PbTe}_{0.9988} \mathrm{I}_{0.0012}$ samples were prepared by melting and annealing. Stoichiometric mixtures of highpurity $\mathrm{Pb}, \mathrm{Te}$, and $\mathrm{PbI}_{2}$ were sealed in graphite-coated quartz ampoules under vacuum and heated to $1000{ }^{\circ} \mathrm{C}$. After holding at $1000{ }^{\circ} \mathrm{C}$ for $6 \mathrm{~h}$, the ampoules were coldwater quenched and annealed at $700{ }^{\circ} \mathrm{C}$ for $48 \mathrm{~h}$. The resulting $n$-type $\mathrm{PbTe}$ ingots were then ground into powders by ball milling in an inert atmosphere. The Fe foil, Mo foil with a thickness of $100 \mu \mathrm{m}$ and the NiFeMo alloy (82 $\mathrm{Ni} w \mathrm{t} \%, 15 \mathrm{Fe}$ wt $\%$ and $3 \mathrm{Mo} \mathrm{wt} \%$ ) foil with a thickness of $150 \mu \mathrm{m}$ were first polished by $\mathrm{SiC}$ sandpaper with 240 , 400, 600, and finally 800 grits, and then cleaned with acetone and then isopropanol in an ultrasonic bath. Subsequently, the foils and $n$-type PbTe powders were placed into a graphite die and were assembled into the layered structure $\mathrm{Fe} / \mathrm{PbTe} / \mathrm{Fe}, \mathrm{Mo} / \mathrm{PbTe} / \mathrm{Mo}$, and $\mathrm{NiFeMo} / \mathrm{PbTe} /$ NiFeMo, respectively. The TE elements were sintered by a rapid hot press with argon flow and under a pressure of $40 \mathrm{MPa}$ at 600,700 , or $800{ }^{\circ} \mathrm{C}$ for 60,150 , or $300 \mathrm{~min}$.
The specimens were cooled in the chamber by flowing inert gas. The samples were cooled below $400{ }^{\circ} \mathrm{C}$ for several minutes and to room temperature for around $1 \mathrm{~h}$. After bonding, a part of the $\mathrm{NiFeMo} / \mathrm{PbTe} / \mathrm{NiFeMo} \mathrm{TE}$ elements bonded at $700{ }^{\circ} \mathrm{C}$ for $60 \mathrm{~min}$ was encapsulated in an evacuated silica tube and was aged at $600{ }^{\circ} \mathrm{C}$ for $240 \mathrm{~h}$. Both as-bonded and post-aged samples were cut into cross sections and polished in order to investigate the microstructures of the joints by scanning electron microscope (SEM, ZEISS 1550VP) at Caltech. The distributions of elements were determined by X-ray energy dispersive spectrometer (EDS, Oxford X-Max), and the EDS software AztecEnergy (Oxford Instrument) with the library standards provided by the EDS software vendor was used to transform the EDS line scanning intensity data to composition data. The precise composition of the phases at the interface was detected by an electron-probe micro analyzer (EPMA, JEOL JXA-8200) with independent compositional standards at Caltech. The Seebeck coefficients of bulk PbTe with and without NiFeMo contacts were tested by the high-temperature Seebeck coefficient measurement system at Caltech [8].

\section{Results and discussion}

\section{Bonding of pure $\mathrm{Fe}$ and Mo foils to $n$-type $\mathrm{PbTe}$}

We attempted to bond pure Fe and Mo foils to $n$-type PbTe by a rapid hot press at 600,700 , and $800{ }^{\circ} \mathrm{C}$. Pure Mo foil failed to bond and no reaction product was detected at the $\mathrm{Mo} / \mathrm{PbTe}$ surface. A joint with very poor strength formed at $800{ }^{\circ} \mathrm{C}$ at the $\mathrm{Fe} / \mathrm{PbTe}$ interface. Figure 1 a shows the backscattered electron (BSE) micrograph at the interface of $\mathrm{Fe} /$ PbTe joints which were bonded at $800{ }^{\circ} \mathrm{C}$ for $60 \mathrm{~min}$. It can be observed that no reaction product formed at the interface. Figure 1b corresponds to the EPMA result at the interface of $\mathrm{Fe} / \mathrm{PbTe}$ joints that is shown in Fig. 1a. It shows that during the joint bonding process, Fe atoms diffused a distance of approximately $20 \mu \mathrm{m}$ into the PbTe.

Although tellurides of $\mathrm{Fe}$ and Mo exist, no reaction is expected with $\mathrm{PbTe}$ as we observed. Based on the Fe-Te [9] and Mo-Te [10] binary phase diagrams, several binary phases are found to be stable within these systems, including $\mathrm{Fe}_{1.12} \mathrm{Te}(\beta), \mathrm{Fe}_{0.67} \mathrm{Te}(\delta), \mathrm{FeTe}_{2}(\varepsilon), \mathrm{Mo}_{3} \mathrm{Te}_{4}$, and $\mathrm{MoTe}_{2}(\alpha)$. Table 1 lists the formation Gibbs free energy $\left(\Delta_{\mathrm{f}} G_{\mathrm{T}}\right)$ of $\mathrm{Fe}_{1.12} \mathrm{Te}(\beta), \mathrm{Fe}_{0.67} \mathrm{Te}(\delta), \mathrm{FeTe}_{2}(\varepsilon)$, $\mathrm{Mo}_{3} \mathrm{Te}_{4}, \mathrm{MoTe}_{2}(\alpha)$, and PbTe based on the literatures [1113]. Table 2 contains the calculated results of the reaction Gibbs free energy $\left(\Delta_{\mathrm{r}} G_{\mathrm{T}}\right)$ of the reaction of Fe with PbTe and the reaction of Mo with PbTe. The calculations show that no binary phase can form during the reaction of either $\mathrm{Fe}$ or Mo with $\mathrm{PbTe}$ due to the positive reaction Gibbs free 
energy. This is in agreement with our experimental observation. Even though $\mathrm{Fe}$ and Mo do not form a metallurgically bonded high strength joint with $\mathrm{PbTe}$, it may be possible that they can be used to reduce the reaction rate of some metals with $\mathrm{PbTe}$; for example $\mathrm{Ni} / \mathrm{PbTe}$.
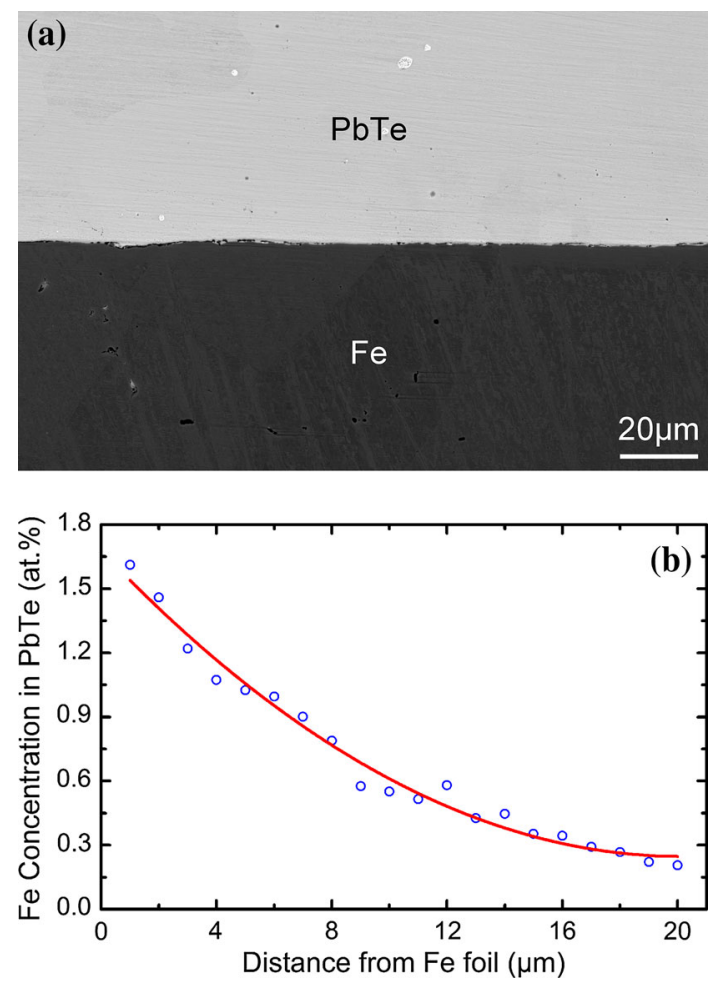

Fig. 1 a SEM micrograph of the interface of $\mathrm{Fe} / \mathrm{PbTe}$ joints bonded at $800{ }^{\circ} \mathrm{C}$ for $60 \mathrm{~min}$; b EPMA result of $\mathrm{Fe}$ concentration in $\mathrm{PbTe}$ from the interface between $\mathrm{Fe}$ foil and $\mathrm{PbTe}$
Bonding of NiFeMo alloy foil to $n$-type $\mathrm{PbTe}$

Figure $2 \mathrm{a}, \mathrm{b}$ shows the BSE micrographs at the interface of the $\mathrm{NiFeMo} / \mathrm{PbTe}$ joints that were bonded at $600{ }^{\circ} \mathrm{C}$ for $300 \mathrm{~min}$. The micrographs reveal the presence of a porous layer with cracks between the NiFeMo foil and $\mathrm{PbTe}$,
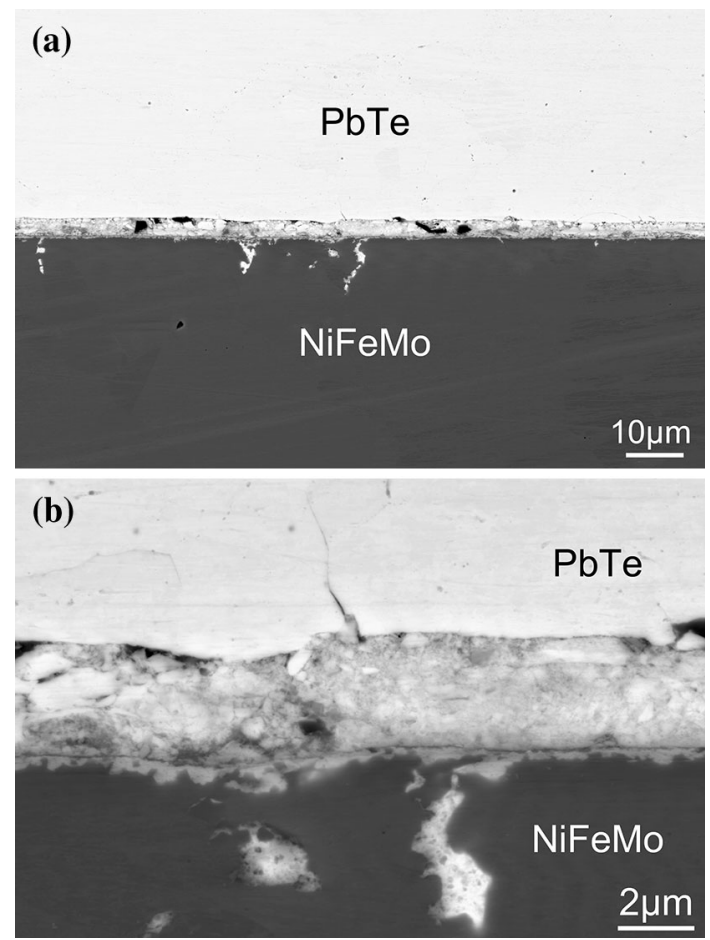

Fig. $2 \mathrm{SEM}$ micrographs of the interface of $\mathrm{NiFeMo/PbTe}$ joints bonded at $600{ }^{\circ} \mathrm{C}$ for $300 \mathrm{~min}$
Table 1 Thermodynamic data of $\mathrm{Fe}_{1.12} \mathrm{Te}, \mathrm{Fe}_{0.67} \mathrm{Te}, \mathrm{FeTe}_{2}$, $\mathrm{Mo}_{3} \mathrm{Te}_{4}, \mathrm{MoTe}_{2}$, and $\mathrm{PbTe}$
Table 2 Calculated

thermodynamic data of the reaction of $\mathrm{Fe}$ with $\mathrm{PbTe}$ and the reaction of Mo with $\mathrm{PbTe}$

\begin{tabular}{lllccc}
\hline Phase label & Formula in reference & Formula used here & Temperature $(\mathrm{K})$ & $\Delta_{\mathrm{f}} G_{\mathrm{T}}(\mathrm{kJ} / \mathrm{mol})$ & Reference \\
\hline $\mathrm{Fe}_{1.12} \mathrm{Te}-\beta$ & $\mathrm{FeTe}_{0.9}$ & $\mathrm{Fe}_{1.12} \mathrm{Te}$ & 1100 & -23.458 & {$[11]$} \\
$\mathrm{Fe}_{0.67} \mathrm{Te}-\delta$ & $\mathrm{Fe}_{0.67} \mathrm{Te}$ & $\mathrm{Fe}_{0.67} \mathrm{Te}$ & 1000 & -21.610 & {$[12]$} \\
$\mathrm{FeTe}_{2}-\varepsilon$ & $\mathrm{FeTe}_{2}$ & $\mathrm{Fe}_{0.5} \mathrm{Te}$ & 900 & -18.527 & {$[11]$} \\
$\mathrm{Mo}_{3} \mathrm{Te}_{4}$ & $\mathrm{Mo}_{3} \mathrm{Te}_{4}$ & $\mathrm{Mo}_{0.75} \mathrm{Te}$ & 1100 & -38.057 & {$[13]$} \\
$\mathrm{MoTe}_{2}-\alpha$ & $\mathrm{MoTe}_{2}$ & $\mathrm{Mo}_{0.5} \mathrm{Te}$ & 1100 & -32.942 & {$[13]$} \\
$\mathrm{PbTe}$ & $\mathrm{PbTe}$ & $\mathrm{PbTe}$ & 900 & -56.067 & {$[11]$} \\
& & 1000 & -51.630 & {$[11]$} \\
& & & 1100 & -47.107 & {$[11]$} \\
\hline
\end{tabular}

\begin{tabular}{lcc}
\hline Chemical reaction equation & Temperature $(\mathrm{K})$ & $\Delta_{\mathrm{r}} G_{\mathrm{T}}(\mathrm{kJ} / \mathrm{mol})$ \\
\hline $1.12 \mathrm{Fe}+\mathrm{PbTe} \rightarrow \mathrm{Fe}_{1.12} \mathrm{Te}+\mathrm{Pb}$ & 1100 & 17.649 \\
$0.67 \mathrm{Fe}+\mathrm{PbTe} \rightarrow \mathrm{Fe}_{0.67} \mathrm{Te}+\mathrm{Pb}$ & 1000 & 30.020 \\
$0.5 \mathrm{Fe}+\mathrm{PbTe} \rightarrow \mathrm{Fe}_{0.5} \mathrm{Te}+\mathrm{Pb}$ & 900 & 37.540 \\
$0.75 \mathrm{Mo}+\mathrm{PbTe} \rightarrow \mathrm{Mo}_{0.75} \mathrm{Te}+\mathrm{Pb}$ & 1100 & 9.050 \\
$0.5 \mathrm{Mo}+\mathrm{PbTe} \rightarrow \mathrm{Mo}_{0.5} \mathrm{Te}+\mathrm{Pb}$ & 1100 & 14.165
\end{tabular}




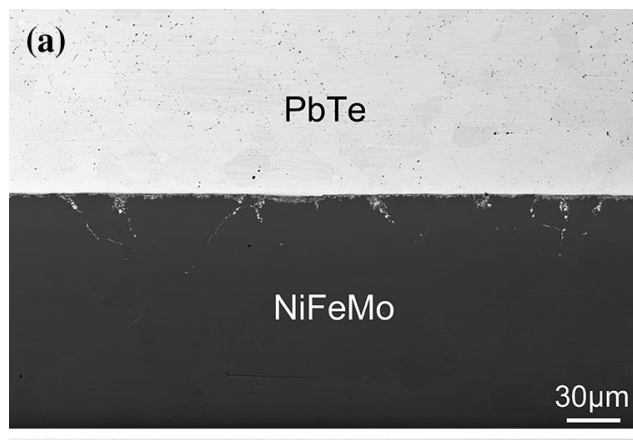

(c)

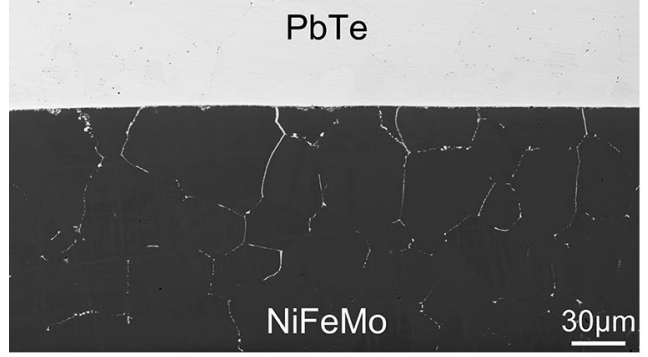

(e)

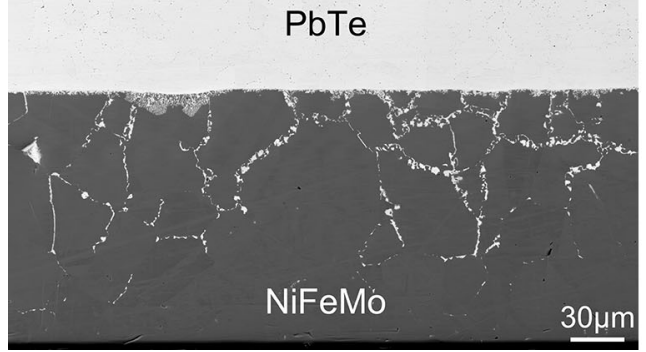

(b)

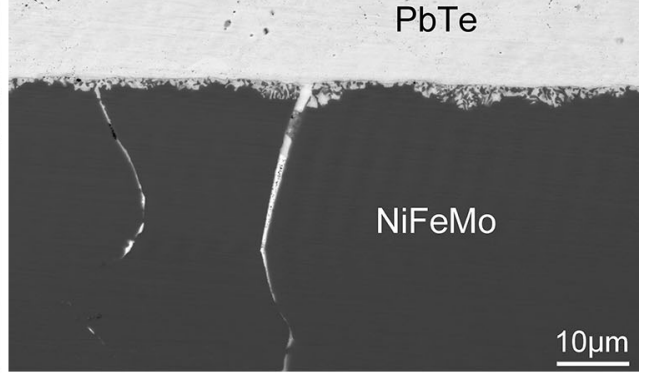

(d)

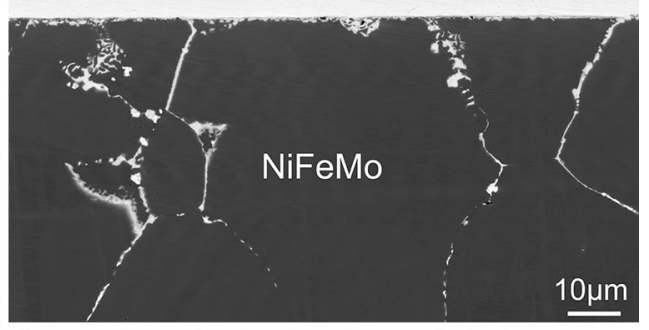

(f)

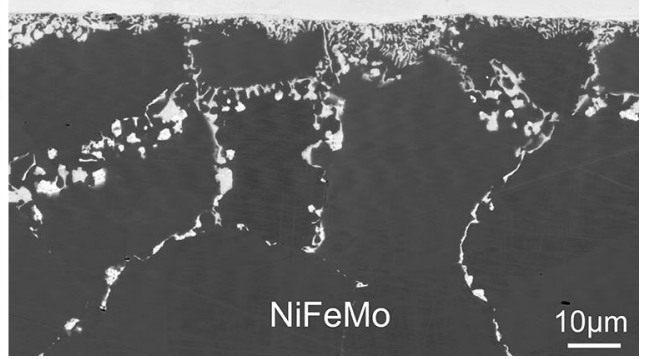

Fig. 3 SEM micrographs of the interface of NiFeMo/PbTe joints bonded at $700{ }^{\circ} \mathrm{C}$ for a, b $60 \mathrm{~min}$; c, d $150 \mathrm{~min}$; and e, f $300 \mathrm{~min}$

which indicates that at $600{ }^{\circ} \mathrm{C}$ the NiFeMo alloy foil does not make a good bond with PbTe. Figure $3 \mathrm{a}$, b shows the $\mathrm{BSE}$ micrographs at the interface of the $\mathrm{NiFeMo} / \mathrm{PbTe}$ joints that were bonded at $700{ }^{\circ} \mathrm{C}$ for $60 \mathrm{~min}$. Under these conditions, the NiFeMo alloy foil bonds well to $n$-type PbTe. No porous layer can be found between the NiFeMo alloy foil and PbTe. However, some material, which presumably consists mostly of PbTe, slightly diffuses into the NiFeMo grain interiors and the NiFeMo grain boundaries. Figure $3 \mathrm{c}, \mathrm{d}$ shows the BSE micrographs at the interface of the $\mathrm{NiFeMo} / \mathrm{PbTe}$ joints bonded at $700{ }^{\circ} \mathrm{C}$ for $150 \mathrm{~min}$. With increasing bonding time, the aforementioned material diffuses nearly throughout the NiFeMo alloy foil, along its grain boundaries. The BSE micrographs at the interface of the $\mathrm{NiFeMo} / \mathrm{PbTe}$ joints bonded at $700{ }^{\circ} \mathrm{C}$ for $300 \mathrm{~min}$ are shown in Fig. 3e, f. The micrographs show that the width of the material along the NiFeMo grain boundaries becomes larger, which will eventually lead to the separation of the NiFeMo grains and the subsequent failure of the joint.
Figures 4 and 5 show the EDS mapping and line scanning results of the interface of $\mathrm{NiFeMo} / \mathrm{PbTe}$ joints that were bonded at $700{ }^{\circ} \mathrm{C}$ for $300 \mathrm{~min}$. The microstructure presented in Fig. 4a suggests that a eutectic liquid phase between NiFeMo foil and PbTe might form during the bonding process. The melting point of PbTe is $924^{\circ} \mathrm{C}$, and based on the literature, the eutectic temperature of $\mathrm{Fe}-$ PbTe (16 at.\% Fe) is $857{ }^{\circ} \mathrm{C}$ [14] while the eutectic temperature of $\mathrm{Ni}-\mathrm{PbTe}\left(8\right.$ at.\% Ni) is $624{ }^{\circ} \mathrm{C}$ [15]. According to our bonding experiment of $\mathrm{Fe} / \mathrm{PbTe}$ joints, the eutectic temperature of $\mathrm{PbTe}-\mathrm{Fe}$ should be above $800{ }^{\circ} \mathrm{C}$, which is consistent with the aforementioned literature value. Additionally, in our previous study of $\mathrm{Ni} / \mathrm{PbTe}$ joints [6], a liquid phase formed at the $\mathrm{Ni} / \mathrm{PbTe}$ interface at $650{ }^{\circ} \mathrm{C}$, which subsequently led to the formation of a ternary phase. Further investigation of the $\mathrm{Ni} / \mathrm{PbTe}$ interface revealed that the liquid phase forms rapidly at interface, and at $700{ }^{\circ} \mathrm{C}$ the $\mathrm{Ni}$ foil dissolves into the liquid at a high rate. Consequently, the Ni foil will disappear because the liquid phase will be extruded out under the bonding pressure. Based on 

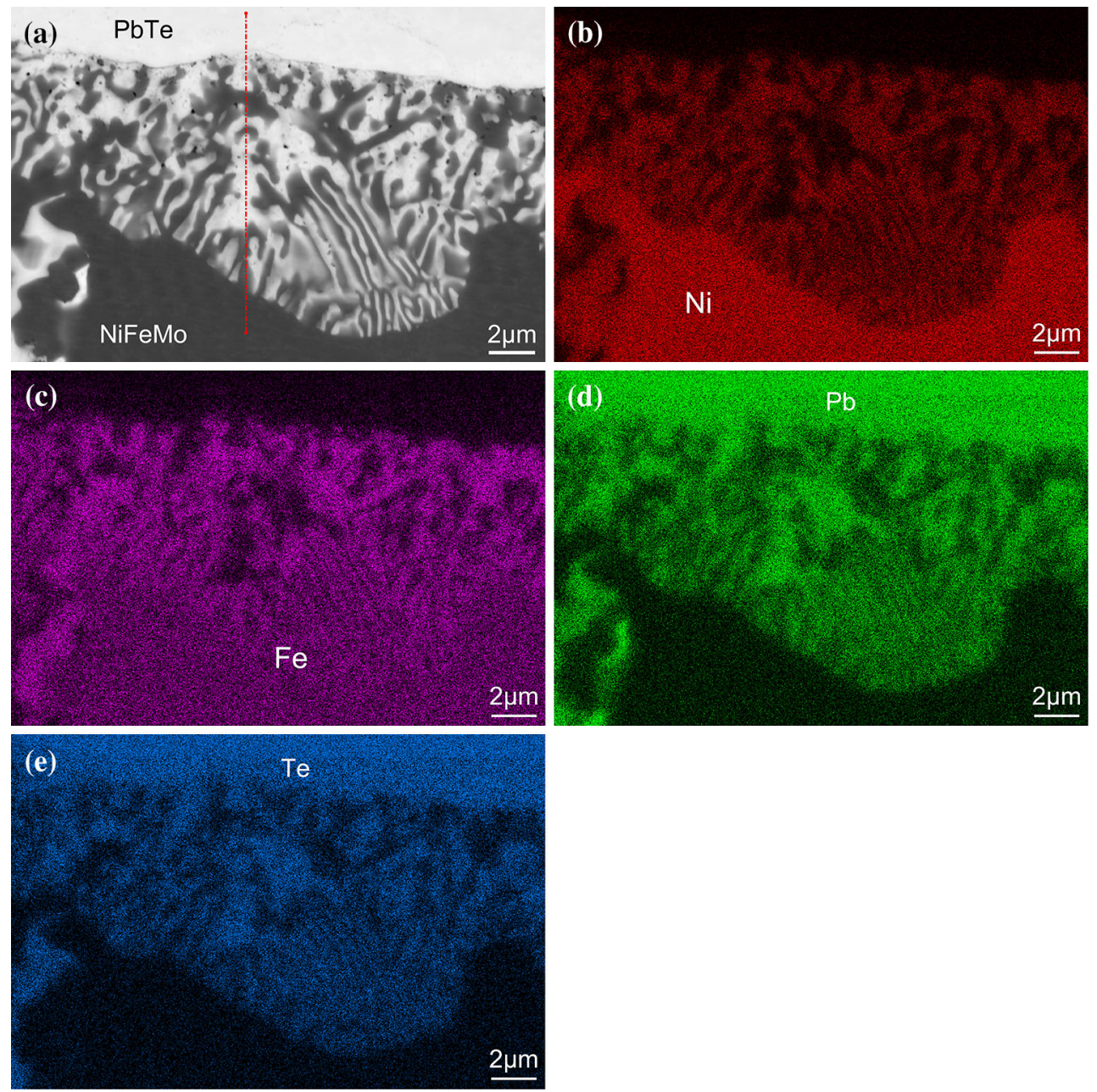

Fig. 4 SEM micrograph and EDS mapping images of the interface of NiFeMo/PbTe joints bonded at $700{ }^{\circ} \mathrm{C}$ for 300 min: a SEM micrograph, b Ni element mapping, c Fe element mapping, $\mathbf{d} \mathrm{Pb}$ element mapping, and $\mathbf{e}$ Te element mapping

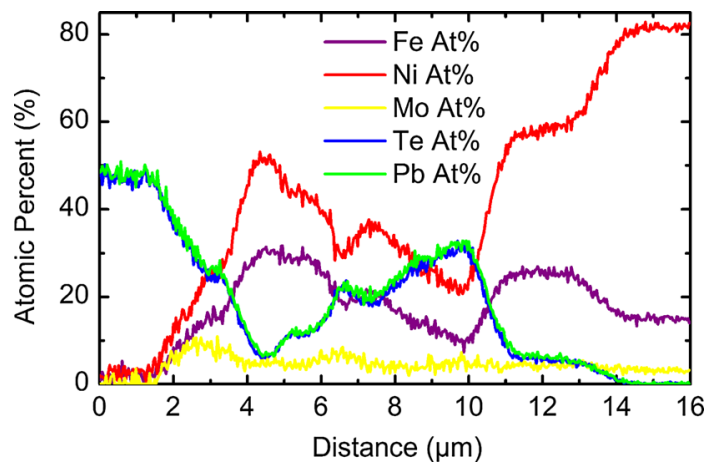

Fig. 5 EDS line scanning result of the interface of $\mathrm{NiFeMo/PbTe}$ joints bonded at $700{ }^{\circ} \mathrm{C}$ for 300 min shown in Fig. 4 a

this information, we conclude that the eutectic temperature of $\mathrm{Ni}-\mathrm{PbTe}$ should be below $700{ }^{\circ} \mathrm{C}$, which is in agreement with the literature value. Hence, due to the similarity of $\mathrm{Ni}$ and $\mathrm{NiFeMo}$, we anticipate that a eutectic liquid phase will also form between the NiFeMo alloy and $\mathrm{PbTe}$, but at a higher temperature. The higher eutectic temperature, due to the presence of $\mathrm{Fe}$ and $\mathrm{Mo}$, suggests that the $\mathrm{NiFeMo} / \mathrm{PbTe}$ joints should have a higher operation temperature compared to $\mathrm{Ni} / \mathrm{PbTe}$ joints.

Figures 6 and 7 show the EDS mapping and line scanning results of the NiFeMo grain boundary region of $\mathrm{NiFeMo} / \mathrm{PbTe}$ joints bonded at $700{ }^{\circ} \mathrm{C}$ for $300 \mathrm{~min}$. Both $\mathrm{PbTe}$ and $\mathrm{Pb}$ are observed in this region. The formation of liquid $\mathrm{Pb}$ is presumably caused by the reaction of $\mathrm{PbTe}$ with NiFeMo and/or the decomposition of PbTe. Although no apparent reaction products, like nickel telluride, are observed at the $\mathrm{NiFeMo/PbTe}$ joints, it can not be concluded that there is no reaction between $\mathrm{PbTe}$ and NiFeMo; the reaction products might be too small to be detected. What is observed though is that a lot of liquid $\mathrm{Pb}$ forms and penetrates along the NiFeMo grain boundaries at the $\mathrm{NiFeMo} / \mathrm{PbTe}$ joints. This is similar to the microstructure developed at the Ni/PbTe joints [6]. 

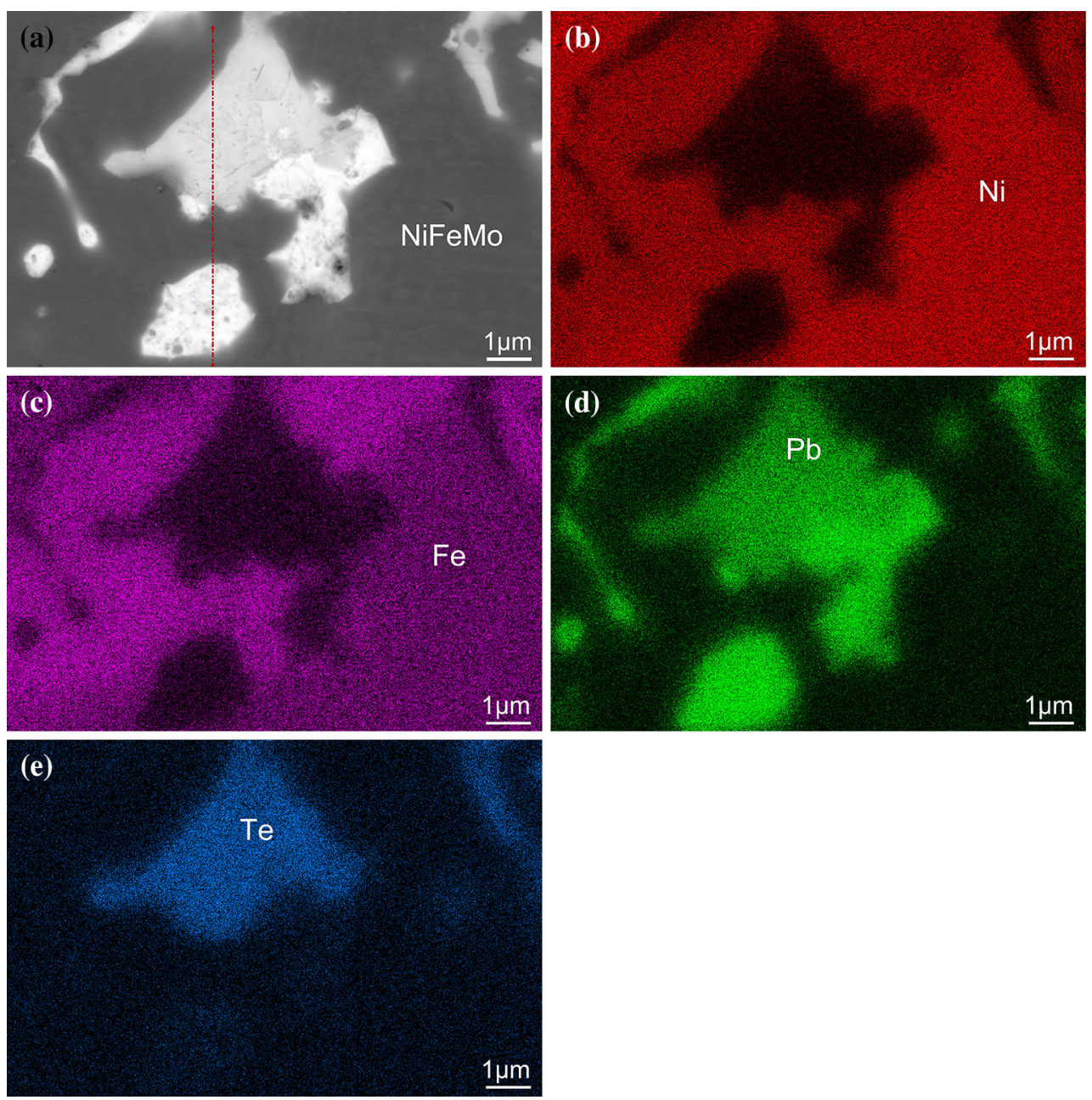

Fig. 6 SEM micrograph and EDS mapping images of the NiFeMo grain boundaries at the NiFeMo/PbTe joints bonded at $700{ }^{\circ} \mathrm{C}$ for 300 min: a SEM micrograph, b Ni element mapping, c Fe element mapping, d Pb element mapping, and e Te element mapping

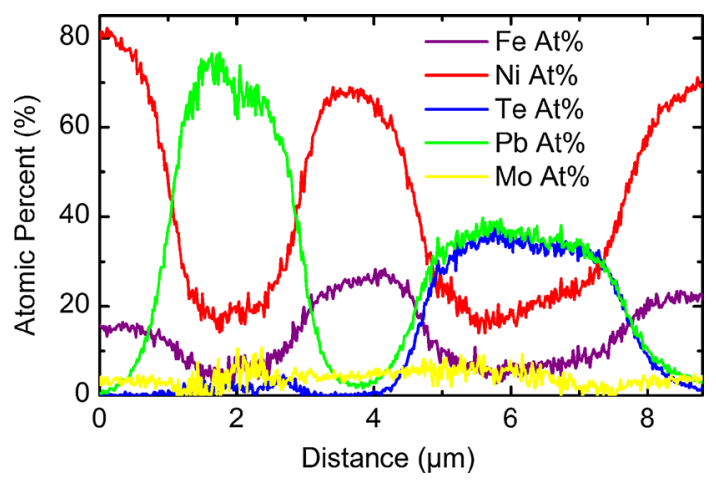

Fig. 7 EDS line scanning result of the NiFeMo grain boundaries at the $\mathrm{NiFeMo} / \mathrm{PbTe}$ joints bonded at $700{ }^{\circ} \mathrm{C}$ for $300 \mathrm{~min}$ shown in Fig. 6a

The formation of the microstructures of $\mathrm{NiFeMo} / \mathrm{PbTe}$ joints bonded at $700{ }^{\circ} \mathrm{C}$ might be caused by two reasons. The main reason might be the eutectic liquid phase formed at the $\mathrm{NiFeMo} / \mathrm{PbTe}$ interface and along the
$\mathrm{NiFeMo}$ grain boundaries and the formed liquid phase $\mathrm{NiFeMo-PbTe}$ infiltrated into the NiFeMo grain boundaries under the high pressure (40 MPa) during the bonding process. That is why $\mathrm{PbTe}$ distributed along the NiFeMo grain boundaries. The secondary reason might be the liquid $\mathrm{Pb}$ caused by the reaction of $\mathrm{PbTe}$ with $\mathrm{NiFeMo}$ and/or the decomposition of $\mathrm{PbTe}$ penetrated along the NiFeMo grain boundaries and accelerated the $\mathrm{NiFeMo-PbTe}$ melt infiltration. According to the theory of liquid metal penetration (LMP), also named as liquid metal embrittlement (LME) or grain boundary penetration (GBP), the liquid material will penetrate along the grain boundaries of solid material when $2 \gamma_{\mathrm{SL}}<\gamma_{\mathrm{GB}}$, where $\gamma_{\mathrm{SL}}$ is the interfacial energy between solid material and liquid material and $\gamma_{\mathrm{GB}}$ is the grain boundary energy of the solid material. However, the mechanism of LMP is still under study and is likely related to the types of the materials [16]. The penetration process depends on many factors, such as the solubility of the solid element in the liquid 
Table 3 Solubility of $\mathrm{Ni}, \mathrm{Fe}$ and $\mathrm{Mo}$ in liquid $\mathrm{Pb}$

\begin{tabular}{|c|c|c|c|c|c|c|c|}
\hline \multirow[t]{2}{*}{ Solid metal } & \multirow[t]{2}{*}{ Temperature $\left({ }^{\circ} \mathrm{C}\right)$} & \multicolumn{2}{|c|}{ Experimental solubility } & \multirow[t]{2}{*}{ Reference } & \multicolumn{2}{|c|}{ Calculated solubility } & \multirow[t]{2}{*}{ Reference } \\
\hline & & $\mathrm{wt} \%$ & at. $\%$ & & $\mathrm{wt} \%$ & at. $\%$ & \\
\hline \multirow[t]{2}{*}{$\mathrm{Ni}$} & 600 & 0.52 & 1.81 & {$[18]$} & 0.59 & 2.06 & [19] \\
\hline & 700 & 0.76 & 2.63 & [18] & 0.87 & 3.00 & [19] \\
\hline \multirow[t]{2}{*}{$\mathrm{Fe}$} & 600 & $2.44 \times 10^{-4}$ & $9.05 \times 10^{-4}$ & {$[18]$} & $1.34 \times 10^{-4}$ & $4.98 \times 10^{-4}$ & [19] \\
\hline & 700 & $6.23 \times 10^{-4}$ & $23.1 \times 10^{-4}$ & [18] & $5.53 \times 10^{-4}$ & $20.5 \times 10^{-4}$ & [19] \\
\hline \multirow[t]{2}{*}{ Mo } & 600 & $<10^{-6}$ & - & [18] & - & - & - \\
\hline & 700 & $<10^{-6}$ & - & {$[18]$} & - & - & - \\
\hline
\end{tabular}

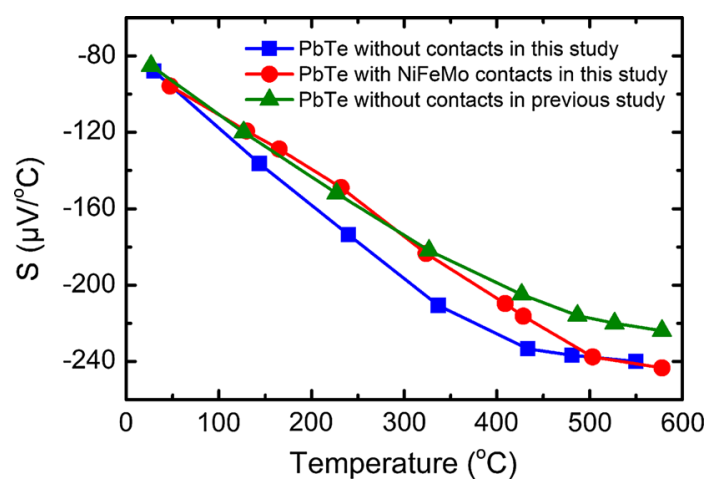

Fig. 8 Seebeck coefficients of bulk PbTe with NiFeMo contacts bonded at $700{ }^{\circ} \mathrm{C}$ for $120 \mathrm{~min}$, bulk PbTe without NiFeMo contacts sintered at $600{ }^{\circ} \mathrm{C}$ for $30 \mathrm{~min}$ in this study and bulk PbTe without $\mathrm{NiFeMo}$ contacts sintered at $550{ }^{\circ} \mathrm{C}$ for $60 \mathrm{~min}$ in previous study material $C_{\mathrm{SL}}$, the diffusivity of the solid element in the liquid material $D_{\mathrm{SL}}$, the solid-liquid interfacial energy $\gamma_{\mathrm{SL}}$, the grain boundary energy of solid material $\gamma_{\mathrm{GB}}$, the solid grain boundary self-diffusion coefficient $D_{\mathrm{GB}}$, temperature $T$ and time $t$ [17]. Table 3 lists the solubility of $\mathrm{Ni}, \mathrm{Fe}$, and $\mathrm{Mo}$ in liquid $\mathrm{Pb}$, which shows that the solubility of $\mathrm{Ni}$ in liquid $\mathrm{Pb}$ is about 1000 times than that of $\mathrm{Fe}$ in liquid $\mathrm{Pb}$, and is about $10^{6}$ times than that of Mo in liquid $\mathrm{Pb}$. Hence, liquid $\mathrm{Pb}$ would easily penetrate into the grain boundaries of $\mathrm{Ni}$, while liquid $\mathrm{Pb}$ is difficult to penetrate into the grain boundary of Mo. Fe has an intermediate resistance to the penetration of liquid $\mathrm{Pb}[20$, 21]. Additionally, the pressure plays a crucial role in the penetration rate. Within a certain scope, a high pressure can accelerate the penetration rate.

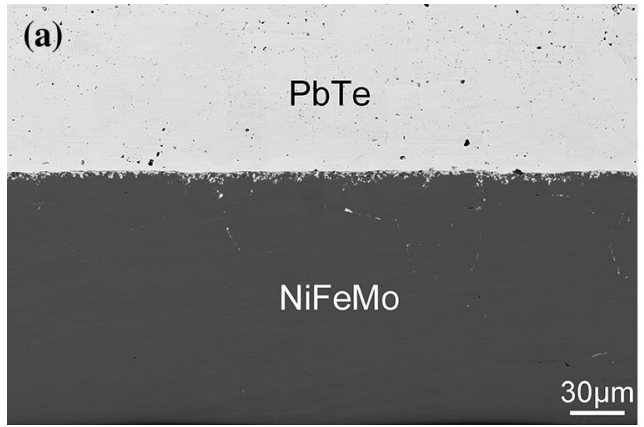

(b)
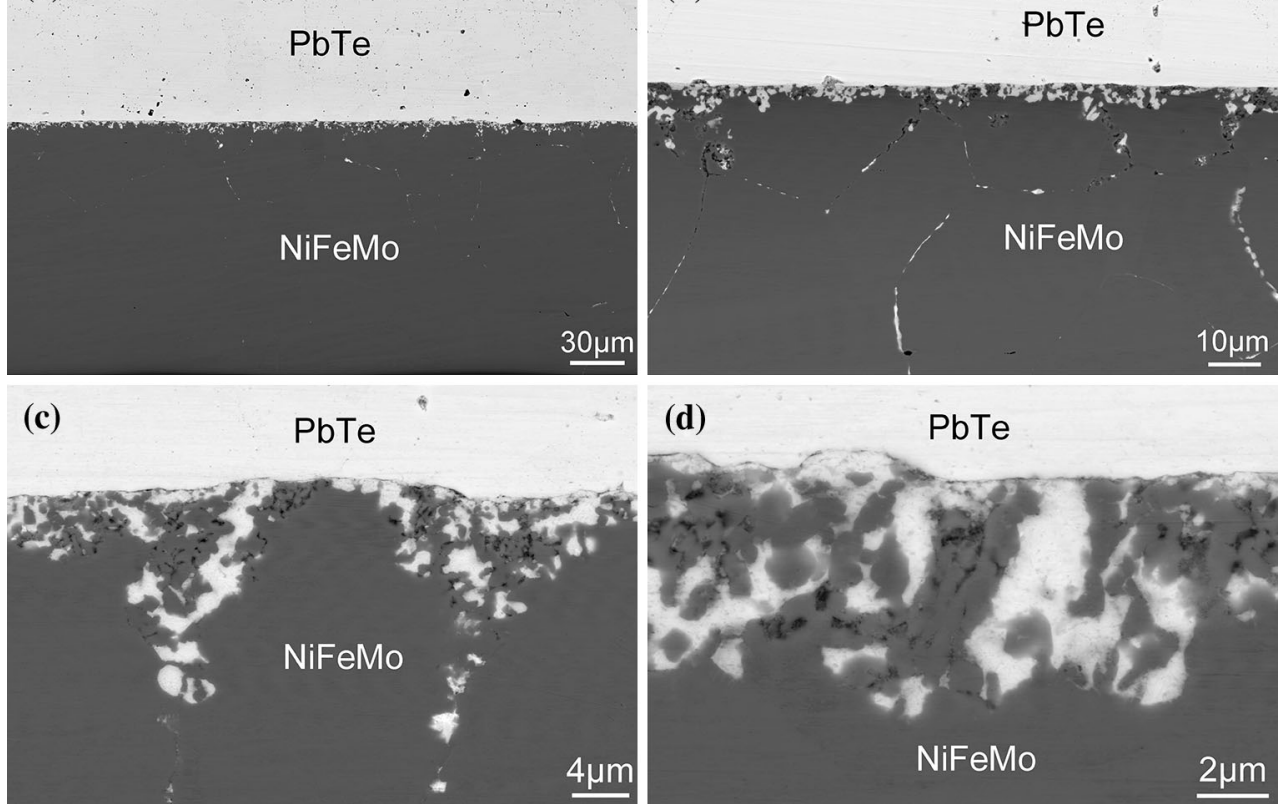

Fig. $9 \mathrm{SEM}$ micrographs of the interface of $\mathrm{NiFeMo} / \mathrm{PbTe}$ joints bonded at $700{ }^{\circ} \mathrm{C}$ for $60 \mathrm{~min}$ after accelerated aging at $600{ }^{\circ} \mathrm{C}$ for $240 \mathrm{~h}$ 
Effect of bonding process on the Seebeck coefficient of bulk PbTe TE materials

Compared to the sintering temperature used for the fabrication of bulk PbTe samples without contacts, commonly about $500-600{ }^{\circ} \mathrm{C}$, the bonding temperature $700{ }^{\circ} \mathrm{C}$ used in this study is higher and might affect the Seebeck coefficient. In addition, the interdiffusion and interface between NiFeMo foil and PbTe might also have an effect on the Seebeck coefficient of bulk PbTe. Thus, in order to investigate the effect of the bonding process, the Seebeck coefficients of bulk $n$-type PbTe without NiFeMo contacts sintered at $600{ }^{\circ} \mathrm{C}$ for $30 \mathrm{~min}$ and bulk NiFeMo/n-type $\mathrm{PbTe} / \mathrm{NiFeMo} \mathrm{TE}$ element bonded at $700{ }^{\circ} \mathrm{C}$ for $150 \mathrm{~min}$ were measured, from room temperature to $600{ }^{\circ} \mathrm{C}$. The measured results are shown in Fig. 8. The Seebeck coefficient of bulk PbTe without contacts sintered at $550{ }^{\circ} \mathrm{C}$ for $60 \mathrm{~min}$ in our previous study [22] is also shown in Fig. 8 for comparison. There is no significant difference between the Seebeck coefficients of these samples, which suggests that the bonding parameters used in this study are appropriate for bonding NiFeMo foil onto $n$-type $\mathrm{PbTe}$.

\section{Accelerated thermal aging of $\mathrm{NiFeMo/PbTe} \mathrm{TE}$} element

The hot side of the PbTe-based TE element commonly operates at $500-550{ }^{\circ} \mathrm{C}$ for several months to decades. For example, the hot side operation temperature of PbTe-based TE modules used in MMRTG is about $538^{\circ} \mathrm{C}$. Above $500{ }^{\circ} \mathrm{C}$, the sublimation, oxidation (if in air), and decomposition of PbTe will become severe and lead to the degradation of the $\mathrm{TE}$ properties of $\mathrm{PbTe}$. The sublimation rate constant of PbTe at $500{ }^{\circ} \mathrm{C}$ is about $9.4 \times 10^{-2} \mathrm{~g} / \mathrm{cm}^{2} \mathrm{~h}$ [23]. In order to investigate the high-temperature reliability of $\mathrm{NiFeMo} / \mathrm{PbTe}$ joints, an accelerated thermal aging test at $600{ }^{\circ} \mathrm{C}$ was conducted in vacuum. Figure 9 shows the $\mathrm{BSE}$ micrographs of the interface of $\mathrm{NiFeMo} / \mathrm{PbTe}$ joints, which were bonded at $700{ }^{\circ} \mathrm{C}$ for $60 \mathrm{~min}$ and then aged at $600{ }^{\circ} \mathrm{C}$ for $240 \mathrm{~h}$. The microstructure is similar with the asbonded joints. However, the formation and penetration rate of eutectic liquid NiFeMo-PbTe and liquid $\mathrm{Pb}$ at $600{ }^{\circ} \mathrm{C}$ without pressure is very slower than that at $700{ }^{\circ} \mathrm{C}$ under $40 \mathrm{MPa}$ pressure. That is because the pressure can accelerate the melt infiltration during the bonding process. According to our observations, the failure mechanism of $\mathrm{NiFeMo/PbTe}$ joints under operation temperature is the continued formation and penetration of eutectic liquid $\mathrm{NiFeMo-PbTe}$ and liquid $\mathrm{Pb}$ along the $\mathrm{NiFeMo}$ grain boundaries, which will lead in the separation of NiFeMo and subsequent contact degradation. If a long lifetime is required for $\mathrm{NiFeMo} / \mathrm{PbTe}$ joints, the hot side operation temperature should not be above $500{ }^{\circ} \mathrm{C}$.

\section{Conclusions}

Fe and Mo foils are difficult to form a metallurgical bonded high strength joint with PbTe. The thermodynamic calculations show that no binary phase can form during the reaction of $\mathrm{Fe}$ or $\mathrm{Mo}$ with $\mathrm{PbTe}$. NiFeMo alloy does not effectively bond to $\mathrm{PbTe}$ at $600{ }^{\circ} \mathrm{C}$, but it does bond at $700{ }^{\circ} \mathrm{C}$. Significant liquid $\mathrm{Pb}$ forms and penetrates along the $\mathrm{NiFeMo}$ grain boundaries at $\mathrm{NiFeMo} / \mathrm{PbTe}$ joints at $700{ }^{\circ} \mathrm{C}$. The Seebeck coefficient of bulk PbTe with $\mathrm{NiFeMo}$ contacts is similar with that without NiFeMo contacts, indicating the bond does not adversely affect the TE properties. The accelerated thermal aging of NiFeMo/ PbTe elements at $600{ }^{\circ} \mathrm{C}$ for $240 \mathrm{~h}$ shows that the failure mechanism of $\mathrm{NiFeMo/PbTe}$ joints under operation temperature is the continued formation and penetration of eutectic liquid NiFeMo-PbTe and liquid $\mathrm{Pb}$ along the NiFeMo grain boundaries.

Acknowledgements Haiyang Xia thanks for the support of Tsinghua Visiting Doctoral Students Foundation and the Opening Project of State Key Laboratory of Advanced Brazing Filler Metals \& Technology (Zhengzhou Research Institute of Mechanical Engineering). This work was supported under the DOW bridge program at Caltech.

\section{References}

1. Abelson RD (2006) Space missions and applications. In: Rowe DM (ed) Thermoelectric handbook: macro to nano. CRC Press, Boca Raton, pp 56-57

2. LaLonde AD, Pei YZ, Wang H, Snyder GJ (2011) Lead telluride alloy thermoelectrics. Mater Today 14:526-532

3. Isotopes nuclear system division (1969) TAGS-85/2N RTG power for Viking lander capsule. Teledyne Company, Baltimore

4. Caillat $\mathrm{T}$ (2005) Advanced thermoelectric power generation technology development at JPL. In: 3rd European conference on thermoelectrics, September 2005, Nancy, France

5. Orihashi M, Noda $Y$, Chen LD, Kang YS, Moro A, Hirai T (1998) $\mathrm{Ni} / n$-PbTe and $\mathrm{Ni} / \mathrm{p}-\mathrm{Pb}_{0.5} \mathrm{Sn}_{0.5} \mathrm{Te}$ joining by plasma activated sintering. In: Proceedings of 17 th international conference on thermoelectrics, Nagoya, Japan, p 543

6. Xia HY, Drymiotis F, Chen CL et al (2014) Bonding and interfacial reaction between $\mathrm{Ni}$ foil and $n$-type $\mathrm{PbTe}$ thermoelectric materials for thermoelectric module applications. J Mater Sci 49:1716-1723. doi:10.1007/s10853-013-7857-9

7. Eiss AL (1966) Thermoelectric bonding study. NASA, Washington, DC

8. Iwanaga S, Toberer ES, LaLonde A, Snyder GJ (2011) A high temperature apparatus for measurement of the Seebeck coefficient. Rev Sci Instrum 82:063905

9. Okamoto H, Tanner LE (1990) Fe-Te (iron-tellurium). In: Massalski TB (ed) Binary alloy phase diagrams. ASM International, Materials Park, pp 1781-1783

10. Brewer L, Lamoreaux RH (1990) Mo-Te (molybdenum-tellurium). In: Massalski TB (ed) Binary alloy phase diagrams. ASM International, Materials Park, pp 2675-2676

11. Barin I (1995) Thermochemical data of pure substances, 3rd edn. $\mathrm{VCH}$, Weinheim 
12. Ball RGJ, Dickinson S, Cordfunke EHP, Konings RJM (1992) Thermochemical data acquisition part 2: joint final report. The Commission of the European Communities, Brussels

13. Mallika C, Sreedharan OM (1990) Standard Gibbs energy of formation of $\mathrm{Mo}_{3} \mathrm{Te}_{4}$ by EMF measurements. J Nucl Mater 170:246-252

14. Rustamov PG, Abilov CI (1987) Equilibrium diagram of the PbTe-Fe system. Russ J Inorg Chem 32:1016-1018

15. Abilov CI (1989) Projection of the liquidus surface of the $\mathrm{Pb}-\mathrm{Ni}-\mathrm{Te}$ system. Russ J Inorg Chem 34:563-566

16. Wolski K, Laporte V (2008) Grain boundary diffusion and wetting in the analysis of intergranular penetration. Mater Sci Eng A 495:138-146

17. Asl KM, Luo J (2012) Impurity effects on the intergranular liquid bismuth penetration in polycrystalline nickel. Acta Mater 60:149-165
18. Martinelli L, Vanneroy F, Rosado JCD, Hermite DL, Tabarant M (2010) Nickel solubility limit in liquid lead-bismuth eutectic. J Nucl Mater 400:232-239

19. Gossé Stéphane (2014) Thermodynamic assessment of solubility and activity of iron, chromium, and nickel in lead bismuth eutectic. J Nucl Mater 449:122-131

20. Zhang JS (2009) A review of steel corrosion by liquid lead and lead-bismuth. Corros Sci 51:1207-1227

21. Zhang JS, Li N (2008) Review of the studies on fundamental issues in LBE corrosion. J Nucl Mater 373:351-377

22. LaLonde AD, Pei YZ, Snyder GJ (2011) Reevaluation of $\mathrm{PbTe}_{1-x} \mathrm{I}_{x}$ as high performance $n$-type thermoelectric material. Energy Environ Sci 4:2090-2096

23. Yang J, Caillat T (2006) Thermoelectric materials for space and automotive power generation. MRS Bull 31:224-229 